\title{
BESTest for Integrated Outdoor-Indoor Energy Balance Modelling
}

\author{
Mohammed BAKKALI ${ }^{\mathrm{a}, \mathrm{b}, 1}$ and Yasunobu ASHIE ${ }^{\mathrm{c}}$ \\ ${ }^{a}$ The Bartlett School, University College London, UK \\ $\mathrm{b}$ The International University of Rabat, Morocco \\ ${ }^{\mathrm{c}}$ Building Research Institute, Japan
}

\begin{abstract}
In our growing cities, climate change and energy related uncertainties are of great concern. The impact of the Urban Heat Island on comfort, health and the way we use energy still requires further clarification. The outdoor-indoor energy balance model (3D-City Irradiance) presented in this article was developed so as to address these issues. The effects of view factors between urban surfaces on three-dimensional radiation and the effects of fully integrated outdoor-indoor energy balance schemes on heat islands and building indoor thermal loads could be included within different building blocks at a resolution of several metres. The model operated under the 'stand alone' mode. It was tested using the Building Energy Simulation Test (BESTest) which demonstrated good levels of agreement for diurnal and seasonal simulations.
\end{abstract}

\section{Keywords}

Urban Heat Island, three-dimensional radiation, outdoor-indoor energy balance schemes, building blocks, diurnal and seasonal simulations, local climates

\section{Introduction}

The Urban Heat Island (UHI) is a significant physical process that involves a changing built environment including buildings, land cover and human activity. Exhaustive definition of the pros and cons of UHI effects still requires further research and effective mitigation strategies will have to be implemented in order to maintain the positive contributions and remove the undesirable effects [1-5]. The thermal interaction between indoor and outdoor environments through conduction, radiation and convection is essential for a better implementation of micro-climatic boundary conditions. Outdoorindoor energy budget models enable the assessment of the impact of outdoor adjacent air/surface temperatures on building indoor air/surface temperatures by taking into account reflected and emitted radiation from surrounding urban surfaces besides other micro-scale effects. The effect of indoor conditions on outdoor environments can also be determined e.g., via quantifying conductive transient heat, energy demand from heating and cooling loads and related sensible and latent waste heat. Such models can

1 Corresponding Author: The Bartlett, UCL Institute for Environmental Design and Engineering, Central House, 14 Upper Woburn Place, WC1H 0NN London, UK; E-mail: mohammed.bakkali.10@ucl.ac.uk. 
undoubtedly broaden our understanding of the physics behind of the UHI through depicting the patterns of different outdoor turbulent heat fluxes, three-dimensional radiation, waste heat from AC systems, building envelopes and other urban surfaces. In meso-scale meteorology, outdoor-indoor energy budget schemes were recently developed. WRF-Urban was implemented with a multi-scaled coupled BEM and a multilayer urban canopy model (Building Effect Parameterization (BEP)) [6-8]. The threedimensional Meso-scale meteorological Model (MM) was similarly coupled with a onedimensional urban Canopy Model (CM), and a BEM [9, 10]. Likewise, an iterative scheme was developed for coupling EnergyPlus and the Town Energy Balance (TEB) [11]. In micro-scale meteorology, few outdoor-indoor energy balance models have been developed to-date. From urban block to neighbourhood scale, they enable the calculation of heat exchange between indoor and outdoor environments. The effect of thermal radiation and conduction from buildings and ground surfaces were taken into account by some models.

Initially, the Temperature of Urban Facets Indoor-Outdoor Building Energy Simulator (TUF-IOBES) was applied to an idealised domain [12]. Computational Fluid Dynamics (CFD) model (Fluent) was coupled with a thermo-radiative simulation tool (Solene) with a typical application on an urban fragment [13]. A three-dimensional (3D) Computer Aided Design (CAD) based simulation tool was developed for predicting the effect of outdoor thermal environment on building thermal performance in an urban block with detailed morphology $[14,15]$. A CFD model was coupled with three-dimensional radiation and one-dimensional heat conduction schemes in addition to air conditioning heat loads [16-19].

\section{Model Description}

The surface temperature of any building depends essentially on the colour of its surface and that of the surrounding surfaces, its orientation and location, solar radiation, air temperature both outside and inside the buildings and essential meteorological conditions such as air pressure, humidity, wind speed and direction, and finally the thermal properties of different construction materials used to build the walls and roofs of buildings. These parameters led us to study surface temperatures, and to predict them in various urban locations and environmental conditions [1].

\subsection{Inputs and Outputs}

Input data includes weather components, water temperature, building data, construction materials and their thermo physical properties in addition to indoor conditions. Output data encompasses radiation levels, surface temperatures, building thermal loads, energy usage profiles so on and so forth (see, figure 1). 


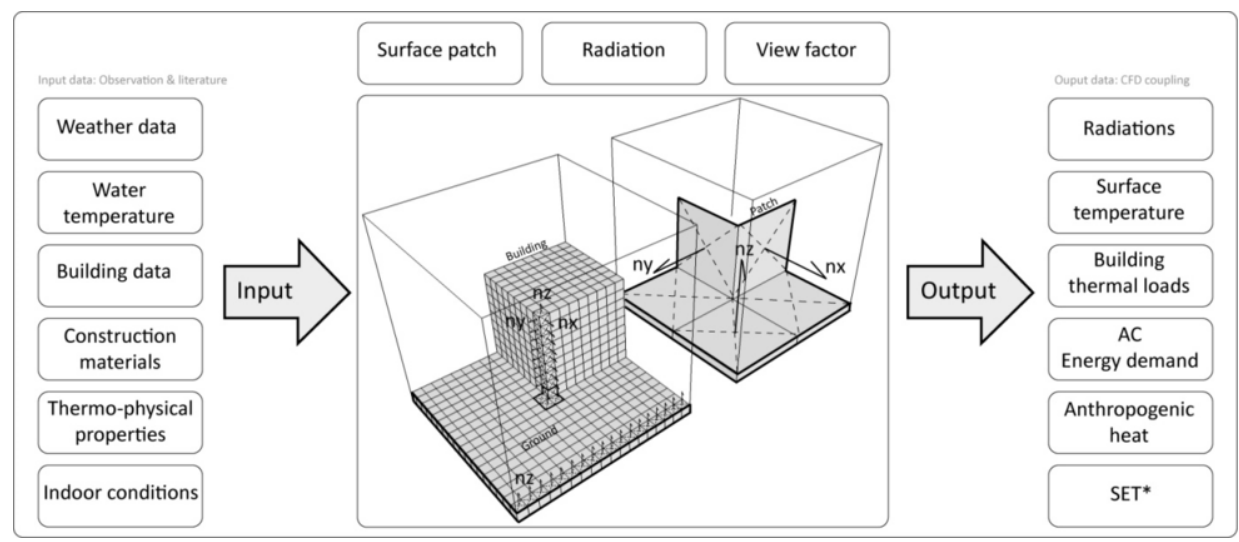

Figure 1. Inputs and Outputs of the heat balance model (3D-City Irradiance)

\subsection{Indoor and Outdoor energy budget}

\subsubsection{Outdoor 3D Irradiation}

The temperature of outdoor urban surfaces is mainly determined by the calculation of atmospheric and solar radiation and air temperature, which is assumed to be hourly uniform, and it is inputted in the boundary conditions. The configuration of shaded/sunlit surface distributions is obtained by using the Ray-Tracing function where a sunlit surface patch has a value of one and a shaded solid surface patch has a value of zero, i.e. no incident solar radiation and it therefore not counted for the calculation of adjacent shortwave length radiation. Mutual reflected short wavelength radiation, emitted and reflected long wavelength radiation between surrounding buildings; urban infrastructures and ground are considered here in the energy budget of the urban canopy. The Monte Carlo Method was used in order to compute view factor values of complicated urban geometries at every solid surface patch. Surface facets were assumed to be grey diffuse surfaces and radiation values were determined through the Radiosity Method, which is more suitable for radiation calculations over larger localities [20].

The governing equations are set as follow:

- Absorbed solar and short wave length radiation from the sun, the atmosphere and the surroundings urban surfaces at every surface patch (eq. 1 -2):

$$
\begin{aligned}
& S_{i}=A_{i} \alpha_{i} I_{i} \quad \text { Where } I_{i}=\beta_{i} I_{\text {direct }} \cos \theta_{i}+F_{S i} I_{\text {diffuse }} \\
& R_{S i}=A_{i} \alpha_{i} \sum_{j=1}^{m} G_{S j} F_{j i} \text { Where } G_{S j}=\left(1-\alpha_{j}\right) \sum_{i=1}^{n} G_{S i} F_{i j}
\end{aligned}
$$

- Net long wave length radiation at different urban surfaces (eq. 3 - 4):

$$
L_{i}=A_{i} F_{S i} \varepsilon_{i} \sigma T_{a}^{4}(a+b \sqrt{e})
$$




$$
R_{L i}=A_{i} \varepsilon_{i}\left(\sum_{j=1}^{m} G_{L j} F_{j i}-\sigma T_{i}^{4}\right) \quad \text { Where } \quad G_{L j}=\varepsilon_{j} \sigma T_{j}^{4}+\left(1-\varepsilon_{j}\right) \sum_{i=1}^{n} G_{L i} F_{i j}
$$

\subsubsection{Outdoor Energy Budget}

Ambient air temperature and wind velocity are uniformly distributed and forced from site measurements or through general circulation and/or regional numerical modelling. Weather conditions are more relevant to the model when wind velocities are lower. Surface temperature at each solid surface patch designated as $i$ is calculated through its energy budget (eq. 5). Latent heat can be considered, for instance, if the solid surface patch $i$ contains water. Conductive transient heat through construction layers in building roofs, walls and ground is calculated by means of the unsteady state one-dimensional thermal conduction equation applied at the normal direction across each solid surface patch $i$ and its constituent construction layers (eq. 6 - 7). The effect of building thermal bridges is not considered here. $G_{i}$ is used for outdoor boundary conditions of solid surface patch $i$. The Finite Difference Method (FDM) is used to fully discrete transient heat conduction in each solid surface patch $i$ and time step t. The implicit Euler Method is used for time discretisation. The Newton Method is used to solve the latter equation especially for long wave radiation. Indoor building surface temperature such as walls, ceilings and floors were then determined accordingly.

- Outdoor energy balance equation at each solid surface patch i:

$$
\begin{aligned}
& S_{i}+R_{S i}+L_{i}+R_{L i}+G_{i}+H_{i}+E_{i}=0 \\
& G_{i}=\left.A_{i} k_{i} \frac{\partial T_{i}}{\partial x}\right|_{x=0}
\end{aligned}
$$

- Unsteady state one-dimensional thermal conduction equation:

$\rho_{i} c_{i} \frac{\partial T_{i}}{\partial t}=\frac{\partial}{\partial x}\left(k_{i} \frac{\partial T_{i}}{\partial x}\right)$

- Sensible heat flux at solid surface patch i:

$H_{i}=A_{i} h\left(T_{\text {adjacent }}-T_{i}\right)$

- Latent heat flux at solid surface patch i:

$E_{i}=A_{i} L \beta h_{q}\left(q_{a}-q_{i}\right)(9)$

\subsubsection{Building Thermal Loads}

In this case, the model determined indoor air temperature through the calculation of building indoor thermal loads via the indoor energy budget. Outdoor and indoor energy balance schemes were dynamically used as mutual boundary conditions (eq. 6 and 11). 
By adding conductive transient heat loads (eq. 11), radiation across windows and other transparent surfaces (eq. 12), ventilation heat loads (eq. 13), indoor generated heat loads from electrical appliances for instance and radiation and convection heat loads from indoor floors (eq. 14), the total building indoor thermal loads was determined (eq. 10). The model simulates indoor generated heat, which is mainly affected by occupant behaviour along with sensible and latent heat from ventilation.

- Building thermal loads are shown in eq. (10) - (14):

$Q=H_{t}+H_{s}+H_{i s}+H_{i \ell}+H_{v s}+H_{v \ell}+H_{f}(10)$

- Transient heat loads at indoor solid surface patch i:

$H_{t}=\sum_{i=1}^{n} A_{i} h_{i}\left(T_{i}-T_{r}\right)$

- Solar heat loads at indoor solid surface patch i:

$H_{s}=\sum_{i=1}^{n} A_{i} \eta_{i} S_{i} \tau_{i} \quad \tau_{i}=e^{-k_{i} \frac{d_{i}}{\cos \theta_{i}}}$

- Heat loads from ventilation:

$H_{v s}=c_{a} \rho_{a} V \eta\left(T_{a}-T_{r}\right) \quad H_{v \ell}=L c_{a} \rho_{a} V \eta\left(q_{a}-q_{r}\right)$

- Reflective and convective heat loads from the floor:

$H_{f}=\sum_{i} A_{f i}\left[\alpha_{f i} S_{i}+h_{f i}\left(T_{f i}-T_{r}\right)\right]$

\section{Building Energy Simulation Test (BESTest)}

Output results from 3D-City Irradiance were compared with other building energy simulation programs. Common boundary conditions were used. They were obtained from the International Energy Agency Building Energy Simulation Test and Diagnostic Method [21]. This procedure aims to methodically test thermal and building energy simulation models. It diagnoses the level of disagreements through a comparative assessment framework based on the features of the building fabric. The Case 600 was used for the testing of annual and daily heating and cooling loads. This case is designated for the assessment of the performance of lightweight building envelope. The building is of a rectangular shape. The widths of south and north elevations are set equally to eight metres. The width of west and east elevations is set to six metres. The height of the building is 2.7 metres. There are no interior partitions inside. The south elevation has 12 $\mathrm{m} 2$ of double-glazed windows. The mechanical system is $100 \%$ efficient with no duct losses, infinite capacity and no latent heat extraction. A dual set point thermostat was set within a dead band between $20^{\circ} \mathrm{C}$ and $27^{\circ} \mathrm{C}$. The weather data was extracted from the 


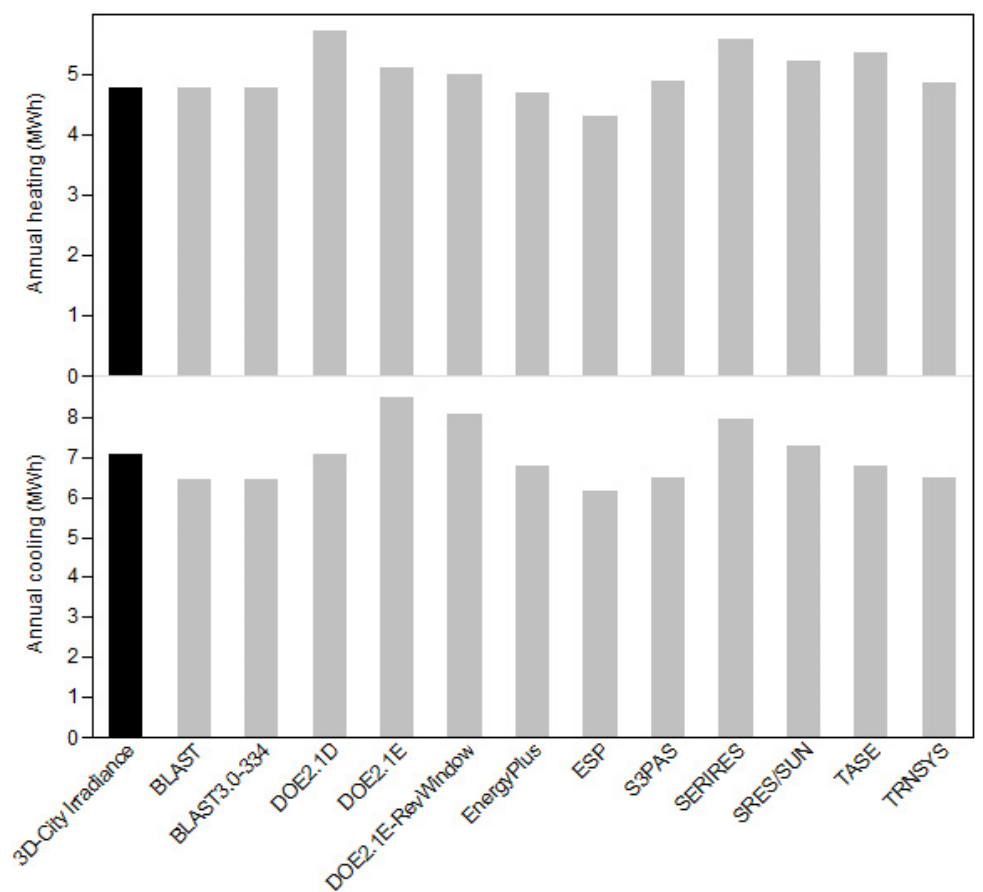

Figure 2. Inter-comparative study between simulated annual heating loads and from different models using BESTest.

Typical Meteorological Year (TMY) in Denver, Colorado. The latitude of the site is 39.8 north, longitude is 104.9 west and altitude is $1609 \mathrm{~m}$. The minimum and maximum annual dry bulb temperature is $-24.39^{\circ} \mathrm{C}$ and $35^{\circ} \mathrm{C}$ respectively. The ground temperature is $10^{\circ} \mathrm{C}$. Detailed information on building construction characteristics and input data can be found in the literature [21]. A comparison of annual and daily heating and cooling loads is presented here. These models cannot reflect building energy use truthfully and the goal is rather to observe if predicted thermal loads fall close to or within the range of results from other programs.

\subsection{Annual heating and cooling loads}

This study compares output results from heating and cooling loads between 13 different models assessed by means of the BESTest (see, figure 2). 3D-City Irradiance calculated a total of $4.77 \mathrm{MWh}$ for annual heating loads. Ten models estimated higher annual heating loads than this value. From higher to lower annual heating loads, these models are DOE2.1D, SERIRES, TASE, SRES/SUN, DOE2.1E, DOE2.1E-RevWindow, S3PAS, TRNSYS, BLAST and BLAST3.0-334 respectively. However, two models have estimated lower annual heating loads than this value, EnergyPlus and ESP.

On the other hand, 3D-City Irradiance calculated a total of 7.09 MWh for annual cooling loads. Four models estimated higher annual cooling loads than this value. From higher to lower annual cooling loads, we find DOE2.1E, DOE2.1E-RevWindow, SERIRES and SRES/SUN respectively. Nonetheless, eight models estimated lower annual cooling loads than this value. From higher to lower annual cooling loads, we find DOE2.1D, 
EnergyPlus, TASE, S3PAS, TRNSYS, BLAST, BLAST3.0-334 and ESP respectively. ESP estimated minimum heating and cooling loads, 4.296 MWh and 6.137 MWh respectively. For maximum annual heating loads DOE2.1D estimated 5.709 MWh and DOE2.1E estimated 8.5 MWh. These results show that 3D-City Irradiance complies with other Building Energy Models (BEMs) for a lightweight building envelope. This is an encouraging outcome that will lead to further testing in the future.

\subsection{Daily heating and cooling loads}

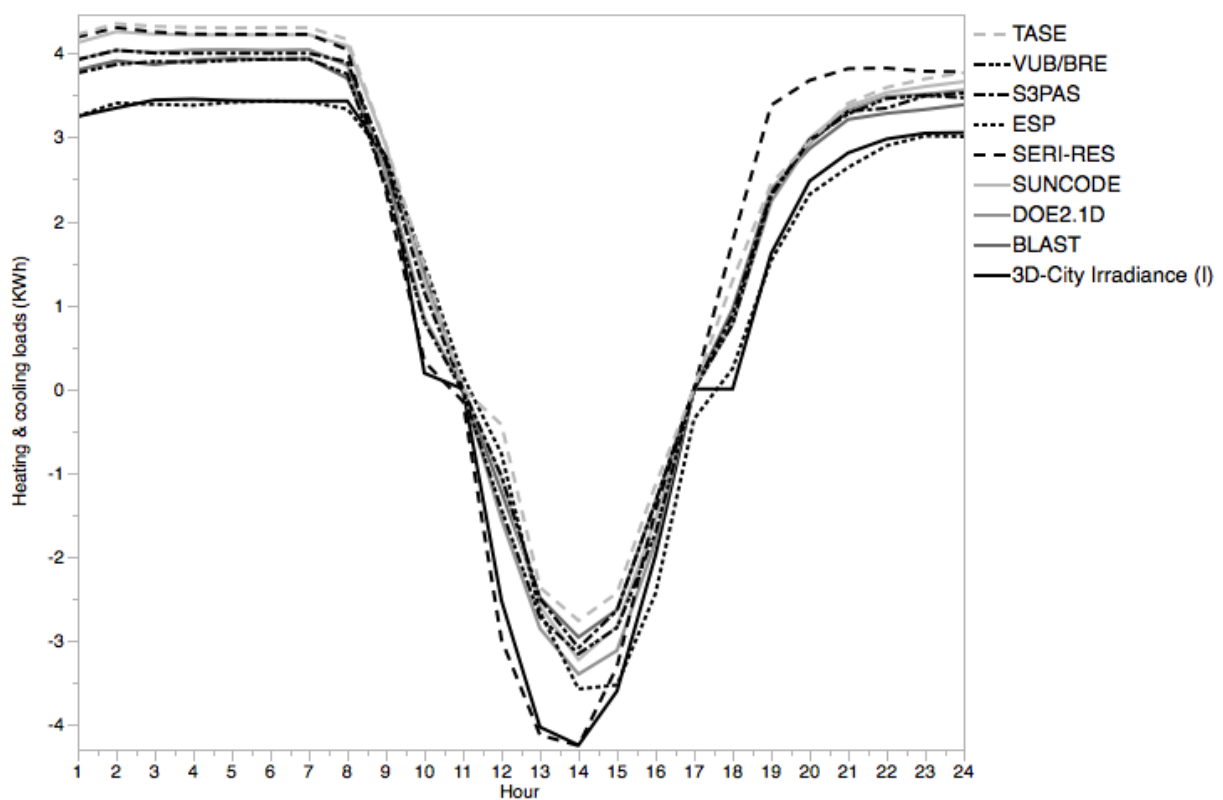

Figure 3. Inter-comparative study between simulated heating and cooling loads from different models using BESTest for one day, 4th January from TMY.

Output results for daily heating and cooling loads from 3D-City Irradiance were compared with eight other models using BESTest on the 4th of January (see, figure 3 ). In this case, values with (-) represent cooling loads and values with $(+)$ represent heating loads. 3D-City Irradiance estimated daily heating and cooling loads within the range of values estimated by other models. Regarding heating loads, the calculated values by the model were closer to those calculated by ESP (lowest values amid the range) and concerning cooling loads, the model calculated values closer to SERI-RES model (highest values amid the range). In order to allow 3D-City Irradiance model to fulfil other requirements of BESTest, an eventual implementation of detailed outdoor convective and indoor convective and radiative heat transfer coefficients are essential. 


\section{Conclusion}

The 3D-City Irradiance model is an outdoor-indoor energy balance model where comprehensive radiative and conductive heat loads within the built environment were assessed comprehensively all together. The model was adapted and further developed to meet the demands of BESTest. The results show that 3D-City Irradiance complies with other Building Energy Models (BEMs) for a lightweight building envelope. This is an encouraging outcome that will lead to further testing in the future. The binary outdoorindoor energy balance approach is vital for the assessment of certain mitigation strategies.

\section{Acknowledgements}

We would like to thank the Japanese Society for the Promotion of Science for funding this research and the Japanese National Institute for Land and Infrastructure Management (NILIM) for hosting this collaboration in Tsukuba City.

\section{References}

[1] Akbari, H., Konopacki, S., 2005. Calculating energy-saving potentials of heat-island reduction strategies. Energy Policy 33, 721-756.

[2] Rosenfeld, A.H., Akbari, H., Bretz, S., Fishman, B.L., Kurn, D.M., Sailor, D., Taha, H., 1995. Mitigation of urban heat islands: materials, utility programs, updates. Energy Build. 22, 255-265.

[3] Mackey, C.W., Lee, X., Smith, R.B., 2012. Remotely sensing the cooling effects of city scale efforts to reduce urban heat island. Build. Environ. 49, 348-358.

[4] Johnson, G.T., Oke, T.R., Lyons, T.J., Steyn, D.G., Watson, I.D., Voogt, J.A., 1991. Simulation of surface urban heat islands under "IDEAL" conditions at night part 1: Theory and tests against field data. Bound.Layer Meteorol. 56, 275-294.

[5] Oke, T.R., Johnson, G.T., Steyn, D.G., Watson, I.D., 1991. Simulation of surface urban heat islands under "ideal" conditions at night part 2: Diagnosis of causation. Bound.-Layer Meteorol. 56, 339-358.

[6] Chen, F., Kusaka, H., Bornstein, R., Ching, J., Grimmond, C.S.B., Grossman-Clarke, S., Loridan, T., Manning, K.W., Martilli, A., Miao, S., Sailor, D., Salamanca, F.P., Taha, H., Tewari, M., Wang, X., Wyszogrodzki, A.A., Zhang, C., 2011. The integrated WRF/urban modelling system: development, evaluation, and applications to urban environmental problems. Int. J. Clim. 31, 273-288.

[7] Salamanca, F., Krpo, A., Martilli, A., Clappier, A., 2010. A new building energy model coupled with an urban canopy parameterization for urban climate simulations-part I. formulation, verification, and sensitivity analysis of the model. Theor. Appl. Clim. 99, 331-344.

[8] Salamanca, F., Martilli, A., 2010. A new Building Energy Model coupled with an Urban Canopy Parameterization for urban climate simulations - part II. Validation with one dimension off-line simulations. Theor. Appl. Clim. 99, 345-356.

[9] Kikegawa, Y., Genchi, Y., Yoshikado, H., Kondo, H., 2003. Development of a numerical simulation system toward comprehensive assessments of urban warming countermeasures including their impacts upon the urban buildings' energy-demands. Appl. Energy 76, 449-466.

[10] Kikegawa, Y., Genchi, Y., Kondo, H., Hanaki, K., 2006. Impacts of city-block-scale countermeasures against urban heat-island phenomena upon a building's energy-consumption for air-conditioning. Appl. Energy 83, 649-668.

[11] Bueno, B., Norford, L., Pigeon, G., Britter, R., 2011. Combining a Detailed Building Energy Model with a Physically-Based Urban Canopy Model. Bound.-Layer Meteorol. 140, 471-489.

[12] Yaghoobian, N., Kleissl, J., 2012. An indoor-outdoor building energy simulator to study urban modification effects on building energy use - Model description and validation. Energy Build. 54, 407417.

[13] Bouyer, J., Inard, C., Musy, M., 2011. Microclimatic coupling as a solution to improve building energy simulation in an urban context. Energy Build. 43, 1549-1559.

[14] Asawa, T., Hoyano, A., Nakaohkubo, K., 2008. Thermal design tool for outdoor spaces based on heat balance simulation using a 3D-CAD system. Build. Environ. 43, 2112-2123.

[15] He, J., Hoyano, A., Asawa, T., 2009. A numerical simulation tool for predicting the impact of outdoor thermal environment on building energy performance. Appl. Energy 86, 1596-1605. 
[16] Huang, H., Ooka, R., Kato, S., 2005. Urban thermal environment measurements and numerical simulation for an actual complex urban area covering a large district heating and cooling system in summer. Atmos. Environ. 39, 6362-6375.

[17] Chen, H., Ooka, R., Harayama, K., Kato, S., Li, X., 2004a. Study on outdoor thermal environment of apartment block in Shenzhen, China with coupled simulation of convection, radiation and conduction. Energy Build. 36, 1247-1258.

[18] Chen, H., Ooka, R., Harayama, K., Kato, S., Li, X., 2004b. Study on outdoor thermal environment of apartment block in Shenzhen, China with coupled simulation of convection, radiation and conduction. Energy Build. 36, 1247-1258.

[19] Bakkali M., Ashie Y., Rans Modelling for Local Climates, Energy Use and Comfort Predictions in Cities. Ambient Intelligence and Smart Environments, Volume 26: Intelligent Environments, 2019, 76 88, doi: 10.3233/AISE190026.

[20] Sparrow, E.M., Cess, R.D., 1978. Radiation heat transfer. Hemisphere Pub. Corp.

[21] Judkoff, R., Neymark, J., 1995. International Energy Agency building energy simulation test (BESTEST) and diagnostic method.

\section{List of Symbols}

$a, b$ [-] Constants from Brunt's formula

$\alpha_{f i}[-]$ Reflectivity of floor

$\alpha_{i}$ [-] Absorption coefficient at solid surface patch $\mathrm{i}$

$A_{i}[\mathrm{~m} 2]$ Area of solid surface patch i

$A_{f i}\left[\mathrm{~m}^{2}\right]$ Area of floor

$\beta$ [-] Evaporation efficiency

$\beta_{i}[-]$ Solar view factor at solid surface patch i

$c_{a}[\mathrm{~J} / \mathrm{kg} . \mathrm{K}]$ Specific heat capacity of air

$\mathcal{C}_{i}[\mathrm{~J} / \mathrm{kg} . \mathrm{K}]$ Specific heat capacity of solid

surface patch $\mathrm{i}$

$C O P$ [-] Coefficient of performance of $\mathrm{AC}$ systems

$e[\mathrm{mmHg}]$ Water vapour pressure

$\mathcal{E}_{i}[-]$ Emissivity of solid surface patch i

$E_{i}\left[\mathrm{~W} / \mathrm{m}^{2}\right]$ Latent heat flux at solid surface patch $\mathrm{i}$

$F_{j i}[-]$ View factor at solid surface patch i

$F_{S i}[-]$ Sky view factor at solid surface patch i

$G_{i}\left[\mathrm{~W} / \mathrm{m}^{2}\right]$ Conductive heat flux at solid

surface patch i

$G_{L j}$ [-] Long wave length radiosity of solid

surface patch $\mathrm{j}$

$G_{S j}$ [-] Total short wave radiosity from solid surface patch $\mathrm{j}$
$h\left[\mathrm{~W} / \mathrm{m}^{2} . \mathrm{K}\right]$ Convective heat transfer coefficient

$h_{f i}\left[\mathrm{~W} / \mathrm{m}^{2} . \mathrm{K}\right]$ Heat transfer coefficient of floor

$h_{i}\left[\mathrm{~W} / \mathrm{m}^{2} . \mathrm{K}\right]$ Convective heat transfer coefficient of solid surface patch i $h_{q}\left[\mathrm{~kg} / \mathrm{m}^{2} . \mathrm{s}(\mathrm{kg} / \mathrm{kg})\right]$ Mass transfer coefficient

$\eta[-]$ Ventilation efficiency of the room

$\eta_{i}$ [-] Surface ratio of window surface patch i to solid surface patch $\mathrm{i}$

$H_{f}[\mathrm{~W} / \mathrm{m} 2]$ Radiated heat loads from floor per building averaged per $\mathrm{m} 2$

$H_{i}\left[\mathrm{~W} / \mathrm{m}^{2}\right]$ Sensible heat flux at solid surface patch $\mathrm{i}$

$H_{i \ell}[\mathrm{W} / \mathrm{m} 2]$ Latent heat generated indoor per building type then averaged per $\mathrm{m} 2$ $H_{i s}[\mathrm{~W} / \mathrm{m} 2]$ Sensible heat generated indoor per building type then averaged per $\mathrm{m} 2[\mathrm{~W} / \mathrm{m} 2]$ $H_{s}$ [W/m2] Solar heat loads per building then averaged per $\mathrm{m} 2$

$H_{t}$

$t$ [W/m2] Transient heat loads through building envelope per building averaged per $\mathrm{m} 2$ $H_{v \ell}[\mathrm{W} / \mathrm{m} 2]$ Latent heat loads from ventilation per building averaged per $\mathrm{m} 2$ $H_{v s}[\mathrm{~W} / \mathrm{m} 2]$ Sensible heat loads from ventilation per building averaged per $\mathrm{m} 2$ $I_{\text {diffuse }}[\mathrm{W} / \mathrm{m} 2]$ Incident diffuse solar radiation $I_{\text {direct }}[\mathrm{W} / \mathrm{m} 2]$ Incident direct solar radiation 
$I_{i}[\mathrm{~W} / \mathrm{m} 2]$ Total direct and diffuse solar radiation at solid surface patch $\mathrm{i}$

$k_{i}[\mathrm{~W} / \mathrm{m} . \mathrm{K}]$ Thermal conductivity

$L[\mathrm{~J} / \mathrm{kg}]$ Latent heat from evaporation

$L_{i}\left[\mathrm{~W} / \mathrm{m}^{2}\right]$ Absorbed long wave length

radiation from the atmosphere

at solid surface patch $\mathrm{i}$

$\rho_{a}\left[\mathrm{~kg} / \mathrm{m}^{3}\right]$ Density of air

$\rho_{i}\left[\mathrm{~kg} / \mathrm{m}^{3}\right]$ Density of solid surface patch i

$q_{a}[\mathrm{~kg} / \mathrm{kg}]$ Specific humidity of ambient air

$q_{i}[\mathrm{~kg} / \mathrm{kg}]$ Specific humidity of solid surface patch i (Mostly ground surface)

$q_{r}[\mathrm{~kg} / \mathrm{kg}]$ Specific humidity of indoor room.

$Q[\mathrm{w} / \mathrm{m} 2]$ Total average indoor thermal loads per building then averaged per $\mathrm{m} 2$

$R_{L i}\left[\mathrm{~W} / \mathrm{m}^{2}\right]$ Absorbed long-wave radiation from urban surroundings and total emitted long wave length radiations from solid surface patch $\mathrm{i}$ $R_{S i}\left[\mathrm{~W} / \mathrm{m}^{2}\right]$ Absorbed short wave radiation from urban surroundings
$S_{i}\left[\mathrm{~W} / \mathrm{m}^{2}\right]$ Absorbed incident solar radiation from the sun and the sky at solid surface patch $\mathrm{i}$ $\tau_{i}$ [ ] Solar transmittance of $i$.

$T_{\text {adjacent }}[\mathrm{K}]$ Temperature of adjacent outdoor air

$T_{a}[\mathrm{~K}]$ Temperature of ambient air

$T_{i}[\mathrm{k}]$ Surface temperature at solid surface patch i

$T_{f i}[\mathrm{k}]$ Surface temperature of floor

$T_{r}[\mathrm{k}]$ Temperaure of indoor room

$T_{i r}[\mathrm{k}]$ Surface temperature of indoor room

$V\left[\mathrm{~m}^{3}\right]$ Volume of room

$W_{\text {heat }}[\mathrm{W} / \mathrm{m} 2]$ Total waste heat from AC systems per building then averaged per $\mathrm{m} 2$ $\theta_{i}$ ${ }^{i}$ [rad] Angle formed by incident direct solar radiation and normal vector of solid surface patch $\mathrm{i}$

$\boldsymbol{\sigma}\left[\mathrm{W} / \mathrm{m}^{2} . \mathrm{K}^{4}\right]$ Stefan-Boltzmann Constant 